\title{
Air weapon fatalities
}

\author{
C M Milroy, J C Clark, N Carter, G Rutty, N Rooney
}

\begin{abstract}
Aims-To describe characteristics of a series of people accidentally and deliberately killed by air powered weapons.

Methods-Five cases of fatal airgun injury were identified by forensic pathologists and histopathologists. The circumstances surrounding the case, radiological examination, and pathological findings are described. The weapon characteristics are also reported.

Results-Three of the victims were adult men, one was a 16 year old boy, and one an eight year old child. Four of the airguns were .22 air rifles, the other a .177 air rifle. Two committed suicide, one person shooting himself in the head, the other in the chest. In both cases the guns were fired at contact range. Three of the cases were classified as accidents: in two the pellet penetrated into the head and in one the chest.
\end{abstract}

Conclusions-One person each year dies from an air powered weapon injury in the United Kingdom. In addition there is considerable morbidity from airgun injuries. Fatalities and injuries are most commonly accidents, but deliberately inflicted injuries occur. Airguns are dangerous weapons when inappropriately handled and should not be considered as toys. Children should not play with airguns unsupervised.

(F Clin Pathol 1998;51:525-529)

Keywords: airguns; injury; death

Air powered weapons were first produced in the middle of the 16 th century, so have been in existence for over 400 years. They have been used as military weapons. The Austrians formed an air rifle corps at the end of the 18th century, which fought with effect at the Battle of Wagram in 1809, although the French won the battle. Air powered weapons were superseded by gunpowder propelled weapons, but are still used for sporting and leisure activities.

Air guns, air pistols, and air rifles may be possessed without a certificate in the United Kingdom if they are not of a type declared dangerous by the Firearms (Dangerous Air Weapons) Rules 1969. An air pistol should discharge a pellet with a kinetic energy below $8.1 \mathrm{~J}(6 \mathrm{ft} \mathrm{lb})$, and an air rifle below $16.3 \mathrm{~J}$ (12 $\mathrm{ft} \mathrm{lb}$ ). Above these levels the weapon is classified as a firearm under Section 1 of the Firearms Act 1968. Guns using compressed gas such as carbon dioxide are classified as firearms. Antique air rifles may occasionally be encountered and are not without their hazards.
Air weapons are often considered to be toys in the United Kingdom, partly because no firearms certificate is required for their possession. Air powered weapons, however, are not without their dangers, and in the United Kingdom there is approximately one fatal incident with an air powered weapon each year, as well as non-fatal injuries. ${ }^{2}$ More than 30000 air weapon injuries are reported in the USA each year and in the five year period up to July 1994 there were 33 air weapon related deaths in USA. $^{34}$

Air weapons in the United Kingdom typically discharge a .177 in $(4.5 \mathrm{~mm})$ or .22 in ( $5.6 \mathrm{~mm}$ ) calibre pellet, but larger pellets up to 0.30 in $(7.62 \mathrm{~mm})$ may be encountered.

We report five deaths caused by air powered weapons seen both by forensic pathologists involved in a suspicious death service and histopathologists who conduct a routine coroner's necropsy practice.

\section{Case 1}

A 22 year old man was found dead in his flat, lying face down on the floor. A .22 Webley Vulcan air rifle was found at his feet. Necropsy examination revealed the presence of an entry wound in the right temple, with a $0.3 \mathrm{~cm}$ diameter hole and a surrounding rim of abrasion $0.3 \mathrm{~cm}$, with no powder staining or

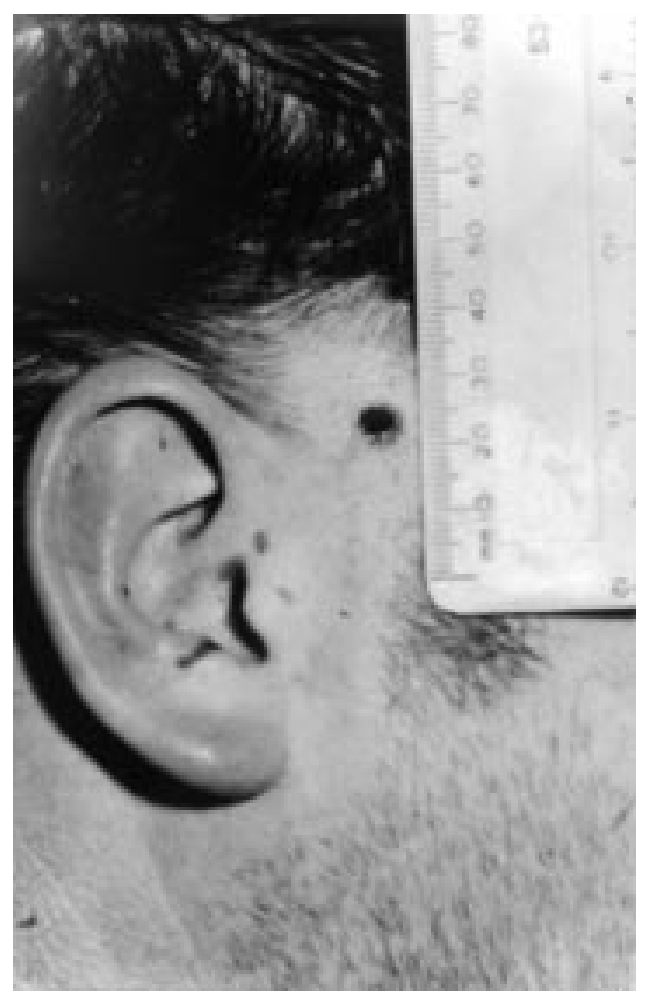

Figure 1.22 pellet entrance wound. Note abrasions on the ear.
Accepted for publication 25 March 1998 


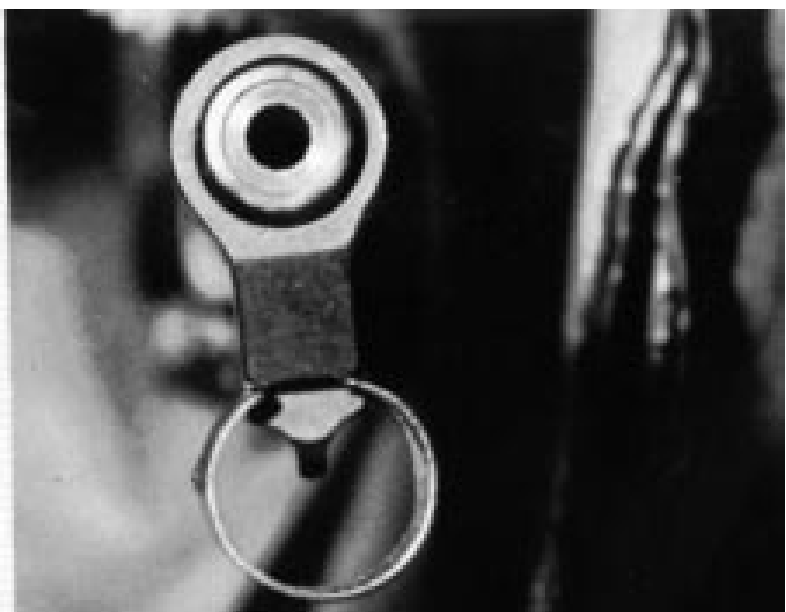

Figure 2 Muzzle and foresight of air rifle.

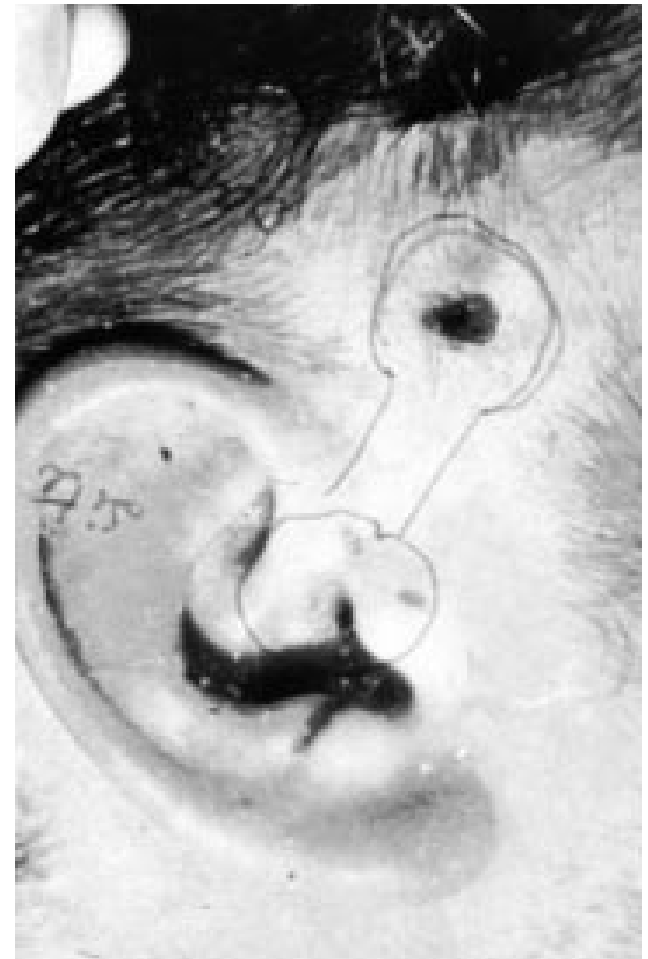

Figure 3 Overlay matching injuries to end of air rifle.

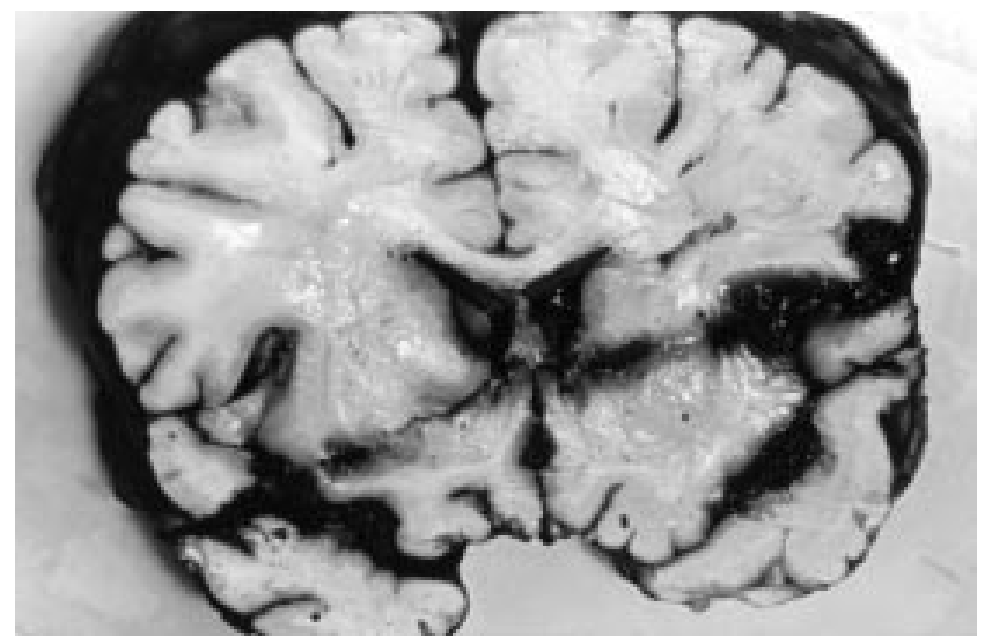

Figure 4 Pellet track through brain.

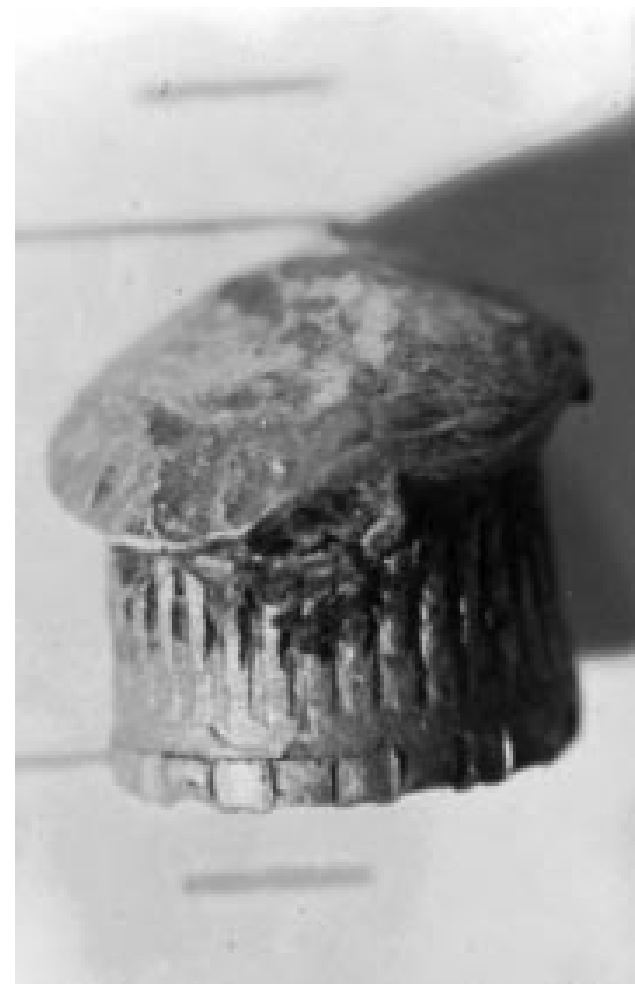

Figure 5 Damaged.22 pellet recovered from the brain.

burning (fig 1). On the outer aspect of the right ear was a collection of vertical, transverse, and horizontal curved abrasions, the lowest of which was $4.5 \mathrm{~cm}$ below the entrance wound. These abrasions corresponded to the foresight guard (figs 2 and 3 ).

A wound tract was identified, passing through the right squamous temporal bone, producing a $0.5 \mathrm{~cm}$ circular defect without any bevelling. The wound tract then passed through the lateral aspect of the right temporal lobe, crossing into the left cerebral hemisphere, exiting through the lateral aspect of the left temporal lobe, then re-entering the brain for 1 $\mathrm{cm}$, where a damaged .22 pellet was recovered (figs 4 and 5).

The blood ethanol at necropsy was 164 $\mathrm{mg} / 100 \mathrm{ml}$. Circumstantial evidence combined with the scene and the necropsy examination findings indicated that this was a case of suicide.

\section{Case 2}

A 23 year old man was playing with an unloaded .177 air pistol, which he pointed at his wife, and pretended to fire. In response she picked up a .177 Fienverkbau air rifle that was in the house. Normally the air rifle was stored empty, but when she cocked and fired the gun, her husband put his hand to his eye and exclaimed that the gun had been loaded. Blood came from his eye and he became unconscious and started fitting. He was taken to hospital. Computed tomography showed a right frontal lobe haematoma. Three pellet fragments were in the orbit and one was in the base of the brain (fig 6). Neurosurgery was performed at which a large haematoma in the right frontal lobe and damage to the anterior communicating artery 


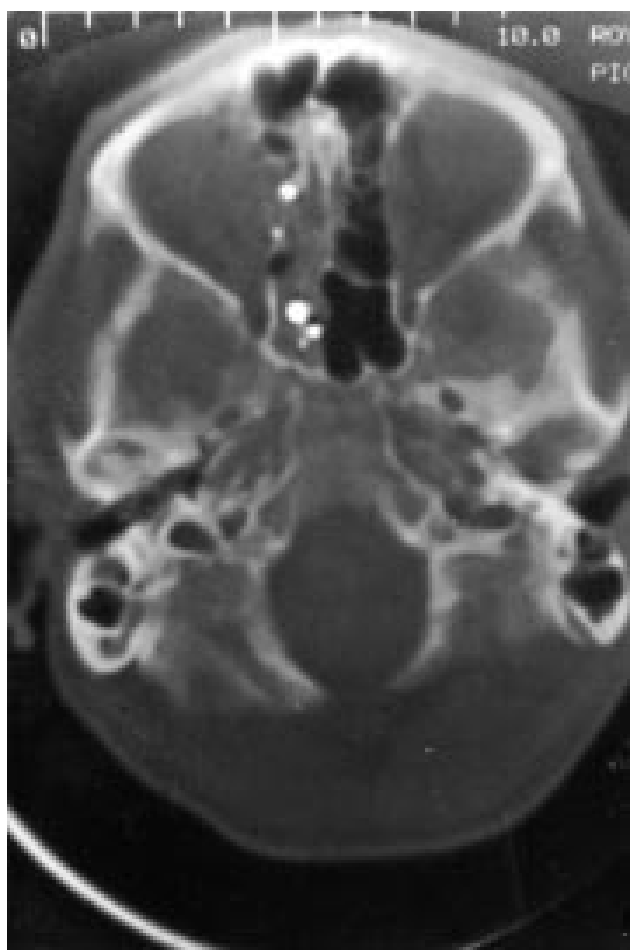

Figure 6 Computed tomography showing main pellet and fragments in the right orbit.

were found. Bleeding was controlled and part of the right frontal lobe was resected, but he did not improve and died four days later.

At necropsy, a wound tract was identified extending from the medial side of the right orbit, the pellet having penetrated the inner aspect of the right upper eye lid, where there was a $0.5 \mathrm{~cm}$ diameter puncture wound. The pellet had entered the cranial cavity through the right anterior cranial fossa adjacent to the cribriform plate. The pellet then entered the right frontal lobe, crossing into the left frontal lobe where the main part of the pellet was recovered.

\section{Case 3}

A 16 year old male was playing with friends, who were firing a .22 air rifle at a book. The book fell over and was replaced by the victim.

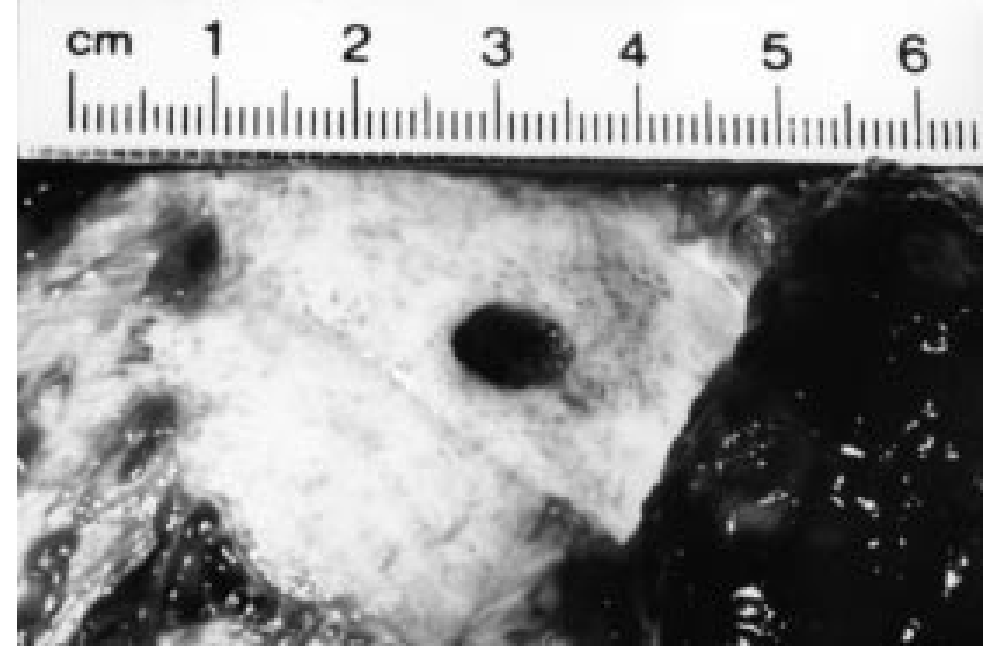

Figure 7 Entrance wound in skull.
As he stood up the air rifle was discharged and he said that he had been hit. He then collapsed and was taken to hospital. A wound was identified in the right temple and computed tomography showed extensive subarachnoid haemorrhage and a pellet lodged near the apex of the left orbit. He did not regain consciousness and was declared brain dead the next day. At firing, the distance between the air rifle and the victim was not more than two metres. At necropsy, an entrance wound was identified in the right temporal region, $0.3 \mathrm{~cm}$ in diameter, with a 0.3 $\mathrm{cm}$ rim of abrasion posteriorly. There was a 0.8 $\times 0.6 \mathrm{~cm}$ defect in the underlying skull with internal bevelling (fig 7). The pellet had entered the brain in the right temporal lobe, crossed the midline and tracked across into the left frontal lobe, where the pellet was recovered. The pellet was a .22 waisted air pellet.

The gun was a Weihrauch .22 inch air rifle. It had been modified so that the safety catch could become disengaged while the gun was being cocked. The trigger pressure had been affected and only $11 / 2 \mathrm{lb}(0.68 \mathrm{~kg})$ was required for firing. The air rifle, however, did not discharge pellets above $12 \mathrm{ft} \mathrm{lb}$ and was not subject to the Firearms (Dangerous Air Weapons) Rules 1969 despite its modifications.

\section{Case 4}

A 10 year old boy was playing with friends in his house. Several adults and children were present in the room. A loaded air rifle was also present in the room and was picked up. It was discharged and an eight year old girl, standing a few feet away from the boy, was hit in the chest. She cried out in pain, walked a few paces and collapsed. She was taken to hospital but resuscitation was unsuccessful. At necropsy, a $0.6 \mathrm{~cm}$ entrance wound was present on the left side of the chest, lateral to the sternum. The pellet had passed through the third intercostal space, through the pericardium, and then into the left ventricle, crossing the heart and exiting into the right chest cavity where it was recovered. The pellet was a .22 inch waisted lead pellet. The gun was a BSA .22 air rifle. The gun was not subject to the Firearms (Dangerous Air Weapons) Rules 1969. Cocking the air rifle required a pressure of $25 \mathrm{lb}(11.34 \mathrm{~kg})$. To fire the trigger a pressure of $4 \mathrm{lb} 12 \mathrm{oz}(2.16 \mathrm{~kg})$ was required. The rifle could only be discharged by pulling the trigger.

\section{Case 5}

A 59 year old man found dead the same evening with a .22 air rifle by his side. Circumstantial evidence pointed to an intention to commit suicide. Necropsy examination revealed a $0.6 \mathrm{~cm}$ hole in a thin cotton shirt he was wearing, with an underlying $0.6 \mathrm{~cm}$ entrance wound in the left side of the chest 6 $\mathrm{cm}$ medial to the nipple (fig 8). There was a ring of surrounding bruising with abrasions at the edge matching the muzzle of the air rifle. The wound track passed through the second intercostal space, $1.5 \mathrm{~cm}$ lateral to the sternum. The wound then involved the pericardium, where there was a $0.8 \mathrm{~cm}$ defect. There was a tense haemopericardium. The intrapericardial 


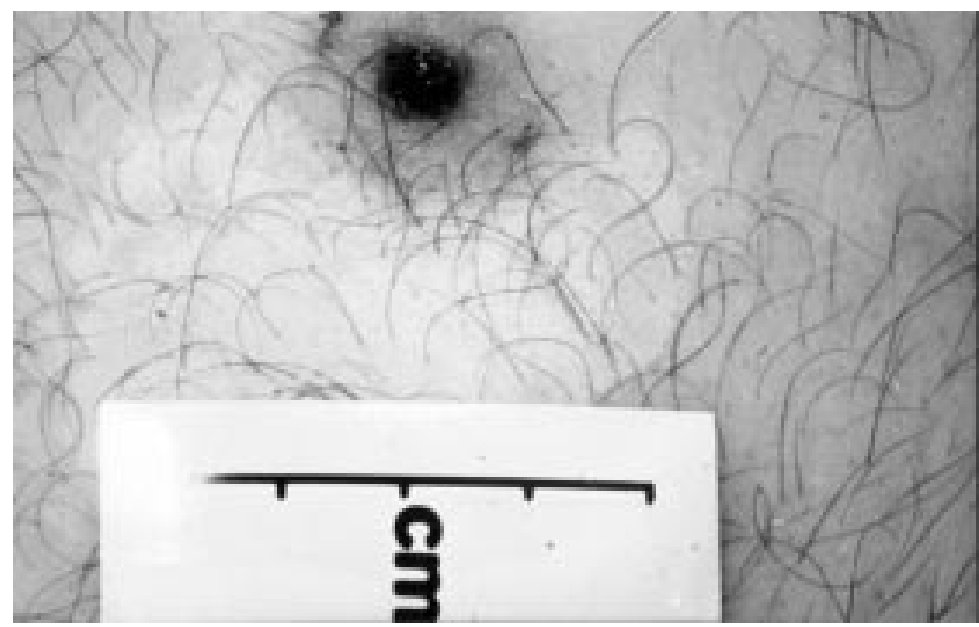

Figure 8.22 pellet entrance wound in chest.

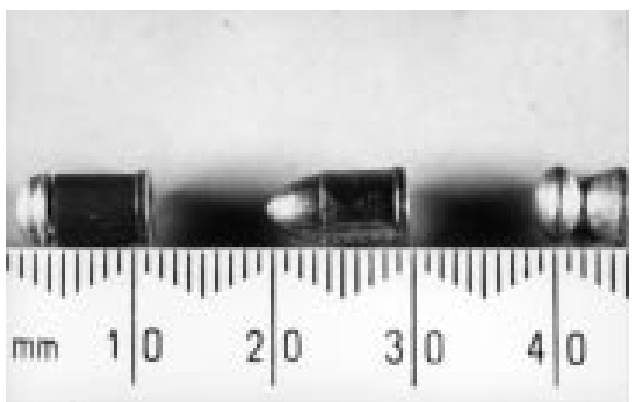

Figure 9 Types of air pellets: plastic with aluminium core, rabbit "magnum," and diabolo waisted.

portion of the ascending aorta had been transfixed by the pellet $5 \mathrm{~cm}$ above the aortic valve, with $0.6 \mathrm{~cm}$ diameter entrance and exit wounds. A .22 waisted pellet was lodged between the aorta and the right main bronchus. The gun was a .22 air rifle with a trigger pressure of $2 \mathrm{lb}(0.91 \mathrm{~kg})$. Test firing showed it to be within the legal limits for muzzle velocity.

\section{Discussion}

Much has been published on the effects of airgun pellets penetrating sensitive organs, particularly the eyes ${ }^{1-16}$ but fewer fatal cases have been reported. ${ }^{2}{ }^{17-32}$

In the United Kingdom, to be lawful an air weapon should propel a pellet with an energy of less than $12 \mathrm{ft} \mathrm{lb}(16.3 \mathrm{~J})$. In seven fatal cases quoted by Warlow, all had energy values below the legal limits, and three of the victims were adults. ${ }^{2}$ In comparison, .22 rimfire cartridges, which are a relatively low velocity powder charged cartridge but of the same calibre as many air powered weapons, have much higher energy values (27 to $111 \mathrm{ft} \mathrm{lb}$ ) with velocities between $650 \mathrm{ft} / \mathrm{s}(198.2 \mathrm{~m} / \mathrm{s})$ and $1710 \mathrm{ft} / \mathrm{s}$ $(521.2 \mathrm{~m} / \mathrm{s})$.

On test firing, one type of American air powered weapon, the Sheridan air rifle, was found to have a range of approximately 340 yards (310 metres). This weapon is designed to fire a .20 Sheridan pellet. In carrying out test firing on sections of beef rib with average thickness of 3-4 $\mathrm{mm}$, the pellets discharged from this weapon did not penetrate. ${ }^{33}$ Most pellets that are fired in the United Kingdom are the diabolo waisted type, although pellets of similar design to the Sheridan .20 pellet may be encountered, such as the "rabbit magnum" for .22 calibre weapons. This ammunition is heavier than waisted pellets, being on average just under $2 \mathrm{~g}$ (average $1.96 \mathrm{~g}$ ). Pellets with a plastic coat and aluminium core are also encountered (fig 9).

The vast majority of fatal cases reported have been with weapons that would be legal in the United Kingdom. However, guns can be modified, increasing the velocity of the pellet. In the case of Buchanan, ${ }^{25}$ the regular oiling of the barrel was felt to have produced the effect of "dieseling," where the addition of oil or diesel fuel is used so that it spontaneously ignites and increases muzzle velocity. We have also encountered a fatal case where an air rifle was modified and used with home made powder ammunition, turning the gun into a home made firearm, or so called "zip" gun.

The majority of fatal incidents reported have involved children under the age of 16 , with boys outnumbering girls. ${ }^{217-32}$ The head is the most common part of the body penetrated. $^{217-2022-27} 293032$ The entrance site may be through the eye, the temple, or the forehead, with the pellet then penetrating the brain. Pellets penetrating the chest have killed by penetrating the heart. ${ }^{2128}{ }^{21}$ In one case the pellet penetrated the aorta, the child dying after five days of monitoring. At necropsy the pellet was found to have transfixed the intrapericardial aorta. ${ }^{31}$ In adults the thicker skull makes the temple and the eye the only sites that can be penetrated by an airgun pellet fired from a normal gun. The abdomen may also be penetrated. ${ }^{2}$

In the investigation of a possible airgun death, the presence of the pellet may have been identified radiologically. Computed tomography has often been performed, as in two cases in this series, and the pellet or its fragments can be located. Airgun pellets do not exit the body, so should always be identifiable whole, or in fragments. These can be examined ballistically like other bullets, and should be retained. ${ }^{2}$ With a .22 weapon, the entrance wound will characteristically be approximately $0.5 \mathrm{~cm}$ in diameter. There may be a small rim of abrasion, but powder burning will not be present, as it would be in a rimfire .22 rifled weapon fired at close range. No skin splitting was seen in these cases, as is seen in firearms, particularly in contact head wounds where discharged muzzle gases tear the skin. If the weapon has been placed against the skin an impression of the muzzle of the gun may be left, as in two cases in this series. The muzzle impression may vary but if the gun is available it should be compared with the wound appearance. If there are any suspicious circumstances the death should be investigated by a forensic pathologist.

The airgun should be examined by a ballistics expert to determine its muzzle energy and the trigger pressure. The trigger pressure may give an indication of the likelihood of an accidental discharge. Most air rifles have trigger pulls of between 3 and $7 \mathrm{lb}$ (1.4 to 3.2 
$\mathrm{kg}$ ), although in more expensive target guns which have adjustable pulls it can be less. ${ }^{2}$

Non-fatal injuries following airgun pellet penetration include significant brain damage leaving permanent impairment. Those involving damage to eyes may result in blindness. In a study from Canada, $60 \%$ of all eye enucleations were due to trauma, with $25 \%$ of all enucleations for trauma being the result of airgun pellet injury. ${ }^{15}$ In one case complete blindness followed the development of sympathetic ophthalmitis in the other eye. ${ }^{8}$ Penetration into the chest or abdomen may require surgical intervention. Airgun pellets, like other projectiles, may undergo embolisation. ${ }^{12-14}$ Retention of the airgun pellet may be associated with long term problems, as in the fatal case of cerebral abscess reported by Shaw and Galbraith, the abscess developing around a pellet and causing death 19 months later when it ruptured. ${ }^{22} \mathrm{~A}$ retained airgun pellet may raise concerns about lead poisoning. Of 11 cases of retained orbital pellets described by Jacobs and Morgan, none had a raised serum lead concentration and it seems unlikely there is a significant risk of lead poisoning from a retained airgun pellet. ${ }^{11} \mathrm{Chil}-$ dren are the most frequent victims of airgun injuries and fatalities, and boys far outnumber girls in all the reported fatal and non-fatal cases. Lack of appropriate supervision is a common feature, as the assailant is most often another child.

Of the five cases presented here, two were suicides and the other three accidents. Accidents far outweigh other reasons for injury and death. However, deliberately inflicted injury does occur, as evidenced by the case of Green and $\mathrm{Good}^{24}$ and one of the cases reported by DiMaio, ${ }^{26}$ where the deaths were considered homicides. Airguns as a weapon of suicide are unusual, but cases have been recorded, as well as unsuccessful attempts. ${ }^{16}$ The adult skull is vulnerable to penetration by airgun pellets, and if the temple region is chosen as the entry site, suicide may be achieved. In the case of Jacob and colleagues, ${ }^{29}$ the temple was the site of entry, as was one of the cases of suicide in this series. The chest is also a potential site for suicide as illustrated by our last case. In the self inflicted injuries in our series, a muzzle impression was left by the weapon, indicating a contact wound. In the suicide reported by Cohle et al, three pellets were fired with one penetrating into the occipital lobe. ${ }^{34}$ The victim also shot himself with a 12 bore shotgun in the chest, presumably because the airgun wounds did not produce the desired effect.

Air powered weapons are readily available in the United Kingdom, being purchasable without a licence. An estimated four million weap- ons are present in households in the United Kingdom. ${ }^{16}$ The damage that air weapons cause is frequently underestimated and they should not be thought of as toys. Children should not be allowed access to guns without full supervision by responsible adults.

1 Usher A, Webster JHH. Aftermath of the Battle of Wagram. Med Sci Law 1964;4:264-6.

2 Warlow TA. Firearms, the law and forensic ballistics. London: Taylor and Francis, 1996.

3 Naude GP, Bongard FS. From deadly weapon to toy and back again: the danger of air rifles. F Trauma 1996;41: 1039-43.

4 Bond SJ, Schnier GC, Miller FB. Air-powered guns: too much firepower to be a toy. 7 Trauma 1996;41:674-8.

5 Rawson HD. The air rifle-a potentially lethal weapon. $N Z$ Med f 1965;64:327-9.

6 Reeves B. Danger of airguns. BMF 1968;i:577-8.

7 Spitz L. Air rifle injuries in children. $S$ Afr Med $f$ 1969;43:557-60.

8 Bowen DI, Magauran DM. Ocular injuries caused by airgun pellets; an analysis of 105 cases. BMF 1973;i:337.

9 James T Pellet gun injuries. S Afr Med f 1973;47:22983000 .

10 Christoffel KK, Tanz R, Sagerman S, et al. Childhood injuries caused by nonpowder firearms. Am $\mathcal{F}$ Dis Child 1984;138:557-61.

11 Jacobs NA, Morgan LH. On the management of retained airgun pellets; a survey of 11 orbital cases. Brf Ophthalmol 1988;72:97-100.

12 Taggart DP, Mackenzie I. Airgun pellet embolism. Scot Med 7 1988;33:340

13 Colquhoun IW, Jamieson MP, Pollock JC. Venous bullet embolisation; a complication of airgun pellets. Scot Med $\mathcal{F}$ 1991;36:16-17.

14 Wascher RA, Gwinn BC. Airgun pellet injury to the heart with retrograde caval migration. F Trauma 1995;38:379-81.

15 Marshall DH, Brownstein S, Addison DJ, et al. Air guns: the main cause of enucleation secondary to trauma in children main cause of enucleation secondary to trauma in children Can f Ophthalmol 1995;30:187-92.

16 Campbell-Hewson G, Egleston CV, Busuttil A. The use of air weapons in attempted suicide. Injury 1997;28:153-8.

17 James WRL. A fatal air rifle pellet wound of the brain. Med Sci Law 1962;2:153-4.

18 Wolff $F$, Laufer $M$. Todliche Kopf schussverletzung durch Luftgewehr. Arch Kriminol 1966;137:78-83.

19 Lal RC, Subrahmanyam BV. Accidental death by air rifle. Forensic Sci Int 1972;1:441-3.

20 Reid IS. Airgun injuries in children. Med $\mathcal{F}$ Aust 1974;1:64-

1 Barnes FC, Helson RA. A death from an air gun. 7 Forensic Sci 1976;19:159-63.

2 Shaw MD, Galbraith S. Penetrating airgun injuries of the head. Br F Surg 1977;64:221-4.

23 Kijewski H, Berg S, Sprung R. Suizid mit Luftgewehr. Untersucungen zur Wunderballistick von Druckluftwaffen. Z Rechtmedizin 1980;84:209-20.

24 Green GS, Good R. Homicide by use of a pellet gun. Am 7 Forensic Med Pathol 1982;4:361-5.

25 Buchanan JD. "Dieseling"-A potentially lethal phenomBuchanan JD. "Dieseling" - A potentially lethal phen
enon in air weapons. Med Sci Law 1982;22:107-10.

26 DiMaio VJM. Gunshot wounds. Practical aspects of firearms, ballistics and forensic techniques. New York: Elsevier, 1985:227-31.

27 Polson CJ, Gee D, Knight B. Essentials of forensic medicine. Oxford: Pergamon Press, 1985:196-7.

8 Ornehult L, Erikson A. Fatal firearm accidents in Sweden. Forensic Sci Int 1987;16:257-6.

29 Jacob B, Huckenbeck W, Daldrup T, et al. Suicides by starter pistols and air guns. Am f Forensic Med Pathol 1990; 11:285-90.

30 Cannabate Reche F, Martin Gonzalez M, Gonzalez-Ripoll Garzon $\mathrm{M}$, et al. Herida mortal por arma de aire comprimodo; presentacion de un caso. Aspectos sociales. An Esp de Pediatr 1993;39:460-2.

31 Fernandez LG, Radhakrishnan J, Gordon RT, et al. Thoracic BB injuries in pediatric patients. $\mathcal{F}$ Trauma 1995; 38:384-9.

32 Pottker TL, Dowd MD, Howard J, et al. Suicide with an air rifle. Ann Emerg Med 1997;29:818-20.

33 Steindler RA. Air gun pellet penetration. Med Sci Law 1980; 20:93-8.

34 Cohle SD, Pickelman J, Conolly JT, et al. Suicide by air rifle and shotgun. F Forensic Sci 1987;32:1113-17. 